\title{
Preoperative detrimental effect on cerebral function of severe congenital heart disease
}

\author{
Andrew C. Chatzis, Evangelia Grisbolaki \\ Department of Paediatric and Congenital Cardiac Surgery, Onassis Cardiac Surgery Centre, Athens, Greece \\ Correspondence to: Andrew C. Chatzis, MD, PhD, FETCS. Department of Paediatric and Congenital Cardiac Surgery, Onassis Cardiac Surgery \\ Centre, 356 Syngrou Ave, Kallithea 17674, Athens, Greece. Email: achatzis@hotmail.gr. \\ Comment on: Lynch JM, Ko T, Busch DR, et al. Preoperative cerebral hemodynamics from birth to surgery in neonates with critical congenital heart \\ disease. J Thorac Cardiovasc Surg 2018. [Epub ahead of print].
}

Submitted Aug 26, 2018. Accepted for publication Sep 04, 2018.

doi: $10.21037 /$ jtd.2018.09.14

View this article at: http://dx.doi.org/10.21037/jtd.2018.09.14

A growing body of evidence suggests that preoperative hypoxia in patients with congenital heart disease (CHD) has significant impact on subsequent postoperative outcomes (1) including, most importantly cerebral damage (2) and, yet not the least, myocardial $(3,4)$ and renal dysfunction (5). Furthermore, the complexity, duration and number of surgical procedures required, constitute a considerable drawback for the developing brain. As a result the approach of complete repair in the neonatal period has been adopted in order to establish a normal circulation as soon as possible (6).

Although hypoxia does not appear to affect early stages of intrauterine life, oxygen becomes a prerequisite for the normal foetal development after the second trimester of gestation. Transient reductions of maternal oxygen supply are compensated through homeostatic redistribution of foetal blood flow to the brain, heart and adrenals while perfusion of the gastrointestinal tract, the kidneys and the lower limbs is reduced (7). If exposure to hypoxia during this stage is prolonged, up-regulation of adaptive mechanisms against oxidative stress takes place. Epigenetic regulation (DNA methylation and demethylation, microRNA's and histone modifications) may affect in-utero stress-induced neuronal and vascular cerebral developmental plasticity in foetuses with CHD, establishing hence a hypoxic/ ischaemic sensitive phenotype in the maturing brain (8). Reduced oxygen supply during midgestation affects cortical development in infants with CHD due to reduced neuroblast migration from the supraventricular zone (SVZ). Experimental evidence suggests that neural stem/ progenitor cells from SVZ have the potential of migration to the injured site of the brain and differentiation into interneurons, restoring thus cortical tissue (9).

After birth, infants with CHD experience a complex of developmental and destructive neurological disturbances dominated by cerebral white matter injury (WMI) a condition similar to periventricular leucomalacia (PVL) of preterm infants (10). Regional brain biochemistry modifications resulting from injury or developmental processes detected by novel optical spectroscopy techniques and brain microstructure alterations estimated through magnetic resonance imaging (MRI) suggest that reduced cerebral oxygen supply slows myelination as a result of destruction of premyelinating oligodendrocyte progenitor cells (pre-OL). This type of glial cell begins to proliferate during the third trimester and presents intrinsic and extrinsic susceptibility to oxidative stress (11). Nonetheless brain microstructure may be altered in infants with CHD, even in the absence of visible injury on MRI (12).

A normothermic, full-term neonate responds to hypoxia with transient hyperventilation, which is sustained in the case of persistent hypoxaemia in the context of critical CHD. As a result more than half of newborns with severe CHD are found to bear acquired focal neurologic abnormalities before surgery (1). Preoperative MRI studies suggest that white matter vulnerability may be related to hypoxia-induced damage in utero (13). During the last decade, increased attention has been drawn to the fact that in the context of CHD perinatal and preoperative periods are critical for the development of cerebral injury (14). Apart from the nature of heart defects per se that affect 
oxygen saturation of the blood supplied to the brain, the length of time of this deleterious exposure obviously renders timing of surgery very important.

Hypoxia associated with CHD leads to brain-sparing hemodynamic redistribution of cerebral blood flow as appears from Doppler measurements of anterior cerebral artery (ACA) pulsatility in foetuses with Transposition of the Great Arteries (TGA) and Hypoplastic Left Heart Syndrome (HLHS) (7). Although these flow adaptations do not ensure a normal postnatal neural and cognitive development, nonetheless, there is evidence that many of the pre- and immediate postoperative lesions resolve within 6 months following surgery (15).

Lynch et al. have previously reported that preoperative cerebral tissue oxygen saturation $\left(\mathrm{ScO}_{2}\right)$ in infants with TGA and HLHS is negatively correlated with a longer time interval between birth and surgery and is associated with an increased risk for postoperative WMI presenting as new or worsening periventricular leukomalacia (PVL) (16). These results are further supported by the results of a recent cohort study from the same group (17). Lynch et al. observed a substantial decrease in $\mathrm{ScO}_{2}$ of $-2.2 \%$ per day in this patient population. Decreased oxygenation was associated with an increase in oxygen extraction, without yet compensatory increase in cerebral blood flow.

In spite, however, the compiling evidence of the time related detrimental effect on the brain of preoperative hypoxia in patients with critical CHD, additional factors should be taken in account while planning treatment. Other organs e.g., liver, kidneys may similarly sustain early hypoxic insult and adequate time is required for them to recover, a prerequisite for surviving a successful repair procedure. Apparently, optimal operative strategy, as regards to timing, is defined as the time interval that provides the best chance of survival in conjunction with the least adverse effects (18).

\section{Acknowledgements}

None.

\section{Footnote}

Conflicts of Interest: The authors have no conflicts of interest to declare.

\section{References}

1. Limperopoulos C, Majnemer A, Shevell MI, et al.
Predictors of developmental disabilities after open heart surgery in young children with congenital heart defects. J Pediatr 2002;141:51-8.

2. Mebius MJ, Kooi EM, Bilardo CM, et al. Brain Injury and Neurodevelopmental Outcome in Congenital Heart Disease: A Systematic Review. Pediatrics 2017;140.

3. Hu J, Sun P, Ruan X, et al. Mechanism of myocardial microvessel formation in cyanotic congenital heart disease. Circ J 2005;69:1089-93.

4. Onwugbufor M, Levy RJ, Zurakowski D, et al. Myocardial cytochrome oxidase activity increases with age and hypoxemia in patients with congenital heart disease. Perfusion 2017;32:306-12.

5. Morgan C, Al-Aklabi M, Garcia Guerra G. Chronic kidney disease in congenital heart disease patients: a narrative review of evidence. Can J Kidney Health Dis 2015;2:27.

6. Jonas RN. Comprehensive Surgical Management of Congenital Heart Disease. 2nd edition. Boca Raton, Florida: CPC Press, 2015.

7. Richardson B, Korkola S, Asano H, et al. Regional blood flow and the endocrine response to sustained hypoxemia in the preterm ovine fetus. Pediatr Res 1996;40:337-43.

8. Ma Q, Zhang L. Epigenetic programming of hypoxicischemic encephalopathy in response to fetal hypoxia. Prog Neurobiol 2015;124:28-48.

9. Morton PD, Korotcova L, Lewis BK, et al. Abnormal neurogenesis and cortical growth in congenital heart disease. Sci Transl Med 2017;9.

10. Mebius MJ, van der Laan ME, Verhagen EA, et al. Cerebral oxygen saturation during the first $72 \mathrm{~h}$ after birth in infants diagnosed prenatally with congenital heart disease. Early Hum Dev 2016;103:199-203.

11. Back SA. Perinatal white matter injury: the changing spectrum of pathology and emerging insights into pathogenetic mechanisms. Ment Retard Dev Disabil Res Rev 2006;12:129-40.

12. Brossard-Racine M, du Plessis A, Vezina G, et al. Brain Injury in Neonates with Complex Congenital Heart Disease: What Is the Predictive Value of MRI in the Fetal Period? AJNR Am J Neuroradiol 2016;37:1338-46.

13. Khalil A, Bennet S, Thilaganathan B, et al. Prevalence of prenatal brain abnormalities in fetuses with congenital heart disease: a systematic review. Ultrasound Obstet Gynecol 2016;48:296-307.

14. Beca J, Gunn J, Coleman L, et al. Pre-operative brain injury in newborn infants with transposition of the great arteries occurs at rates similar to other complex congenital heart disease and is not related to balloon atrial 
septostomy. J Am Coll Cardiol 2009;53:1807-11.

15. Andropoulos DB, Hunter JV, Nelson DP, et al. Brain immaturity is associated with brain injury before and after neonatal cardiac surgery with high-flow bypass and cerebral oxygenation monitoring. J Thorac Cardiovasc Surg 2010;139:543-56.

16. Lynch JM, Buckley EM, Schwab PJ, et al. Time to surgery and preoperative cerebral hemodynamics predict postoperative white matter injury in neonates with

Cite this article as: Chatzis AC, Grisbolaki E. Preoperative detrimental effect on cerebral function of severe congenital heart disease. J Thorac Dis 2018;10(Suppl 33):S3973-S3975. doi: $10.21037 /$ jtd.2018.09.14 hypoplastic left heart syndrome. J Thorac Cardiovasc Surg 2014;148:2181-8.

17. Lynch JM, Ko T, Busch DR, et al. Preoperative cerebral hemodynamics from birth to surgery in neonates with critical congenital heart disease. J Thorac Cardiovasc Surg 2018;156:1657-64.

18. Jonas RA. Should we be doing the Norwood procedure sooner? J Thorac Cardiovasc Surg 2014;148:2188-9. 